\title{
The Effect of Text Typographical Features on Legibility, Comprehension, and Retrieval of EFL Learners
}

\author{
Hassan Soleimani ${ }^{1} \&$ Elham Mohammadi ${ }^{1}$ \\ ${ }^{1}$ Payame Noor University, Tehran, Iran \\ Correspondence: Hassan Soleimani, Department of Applied Linguistics, Payame Noor University, Tehran, Iran. \\ PO box 19395-3697. Tel: 98-912-253-5368. E-mail: Arshia.soleimani@gmail.com
}

Received: May 1, 2012 Accepted: May 18, 2012 Online Published: July 11, 2012

doi:10.5539/elt.v5n8p207 URL: http://dx.doi.org/10.5539/elt.v5n8p207

\begin{abstract}
This experimental study investigated the relationship between font type, font size, and line spacing and legibility, as measured by speed of reading, comprehension, and recalling. Instruments for testing legibility and reading comprehension were presented in eight typographical styles in print. The study tested 90 students for legibility and 76 students for comprehension. The subjects were chosen from Urmia Language Center in Urmia, Iran, and they were both girls and boys. Two weeks after the reading comprehension test, the subjects took part in recalling test. In all tests, the subjects were randomly assigned to one of the eight different typographical styles with Arial or Bookman Old Style (font selection) and 10pt or 12pt (font size). But the subjects had both set solid and double spaced leading in their instruments. Results indicated that the $12 \mathrm{pt}$ was read faster than 10pt. But font selection and line spacing did not have any significant effect on reading speed. Also, there were no significant results with regard to comprehension and recalling.
\end{abstract}

Keywords: typography, legibility, speed of reading, comprehension, recalling

\section{Introduction}

In order to keep informed, people undoubtedly depend on reading material (Aberson \& Bouwhuis, 1977). In English as a foreign language, reading is the major source of input for learners, and instruction mostly takes place through reading. And yet, very little is known about how type features are perceived by the readers. Studies, like this one, are vital to find out the importance of type design and typographical issues in learning and reading through repeatable experimentation. It is more than a century that editors and printers have been concerned with legibility of print. There have been lots of recommendations and ideas regarding legibility, but they were not based on scientific studies and were based on casual observations. Few studies have been done before 1900 but after 1925, the researchers expanded their studies in this area (Tinker, 1963).

Another issue of interest to researchers has always been the probable effect of typography on reading comprehension. Rand Reading Study Group (2002) defines reading comprehension "as the process of simultaneously extracting and constructing meaning through interaction and involvement with written language" (p. 11). RRSG suggests that reading comprehension consists of three factors: the reader, activity, and text. According to Tracey and Morrow (2002), surface features of the text, like the content of the text, the readability of it, and even the font size and font type of the text can influence the interaction of the reader with the text (as cited in Pardo, 2004).

Although different typefaces or fonts have different connotations and can have influence on the readability, interpretation, and the impact of the words they represent (Thangaraj, 2004), for decades there has been a disagreement among the scientists and typographers concerning the best typographical factors used in print. Some important issues to be considered dealing with the best typography choices in print are font type, font size, and leading or the vertical space between the lines (Tinker, 1963). Reviewing the literature below, one could notice there is no agreement among researchers on the best typographical factors.

\section{Literature Review}

\subsection{Legibility, Eye Movement and Speed of Reading}

It is more than two centuries that legibility has been important for editors and typographers. Legibility is related to the capability of a text to be identified properly and it is related to the ease of eyes to detect words and letters 
which is important for data acquisition in reading. Increasing legibility can enhance text acquisition because the first step in the reading process is visually acquiring the information (Sheedy, Subbaram, Zimmerman, \& Hayes, 2005).

Legibility is determined by factors like font face, font size, and spacing (Lee, 2003). Typeface characters have effect on legibility by affecting the way that readers can discern words and letters. Therefore, a greater legibility leads to a greater ability to discern and consequently to a greater ability to read the text. (McCarty \& Mothersbaugh, 2002).

Speed of reading is an important factor to be considered while dealing with legibility. For being legible, a text must be read rapidly and easily (Hughes \& Wilkins, 2000). Legibility is related to perceiving letters and words and reading a text rapidly, easily, and with understanding. Optimal legibility is achieved if the typographical factors, like size of type and leading, together make an easy and rapid reading with comprehension (Tinker, 1963).

Eye-movement measurement is another way to determine the readability of texts both on screen and on paper. The perception of information takes place in saccades. When readers finish one line, their eyes have a sweep to the beginning of the other line which is called return sweep (Nanavati\& Bias, 2005). Leading is one factor that has a great effect on having an easy return sweep. If the space between the lines is not too much or too little, the return sweep occurs easier and faster (Vanderschants, 2008).

\subsection{Legibility, Comprehension, and Recalling}

Comprehension only takes place when the reader has an interaction with the text. For comprehending a text, readers should read the text in the first step (Pardo, 2004). Working memory has a limited capacity (Oberauer \& Kliegl, 2001). Therefore, for giving a chance to short term memory to be able to comprehend the text, there should be some levels of automatic decoding. If too much energy is needed to recognize the words, less mental energy will be left for comprehending (Pardo, 2004).

As mentioned above, reading comprehension is not a simple process and it is definitely an important skill for students in order to succeed. Features of the text affect the interaction between reader and the text for comprehension (Pardo, 2004). Tracy and Morrow (2002, as cited in Pardo, 2004) have introduced "surface structures", like font type and font size, as factors that can influence reader-text interaction. In their idea, features of a text are really important for readers to be able to make meaning. For example, Serif fonts in 16 point are the most preferable ones considering legibility (Hughes \& Wilkins, 2000). Legibility of a text affects its readability which means the ease of comprehension (Mills \& Weldon, 1987). Consequently, it affects reading comprehension (Woods, Davis, \& Scharff, 2005).

Chandler (2001) examined font type and size to investigate their influence on reading speed and comprehension of onscreen reading. He used Palatino and Helvetica in three sizes: 8, 10, and 12-point. Type size was proven to have a significant effect on reading speed. 12- Point was the largest font size and was read faster than other fonts. He believes that larger font was read faster because it had more available pixels for each letter. In his study, there was no significant effect of font type selection on speed of reading. He did not find any effect of type size and font selection on comprehension. He has concluded that the sensitivity of legibility to typeface is more than that of comprehension.

Gasser, Boeke, Haffernan, and Tan (2005) focused on the effect of font type on information recalling. They wanted to find out whether the existence of serifs has any role in information recalling. They used four fonts for finding out their effect on recalling. They used two serif fonts (Courier and Helvetica) and two sans serif fonts (Palatino and Moraco). All materials were typed in 12-point size. Participants were given a text and they were asked some questions. After finishing reading, they were given a questionnaire in order to get attention distraction. Then they answered some questions that estimated the recalling of information. Their study revealed a significant effect of serif fonts on information recalling.

According to Criag and Bevington (1999, as cited in Gasser et al., 2005), markings of serif fonts make the row of lines to be separated more easily, consequently, reading becomes easier. Kanfer and Ackernan (1989, as cited in Gasser et al., 2005) have stated that perceiving rows of a text easier brings about using fewer attentional resources for reading. Then more attentional resources remain for processing the message of the text which results in deeper processing and easier recall of information. Another reason for having the result above could be due to familiarity of the participants with serif fonts (Gasser et al., 2005).

\subsection{Font Selection}

Although readers can read words in different fonts, it is not deniable that recognizing words with some fonts is 
easier than recognizing them with other fonts (Rossum, 1998). "Our written language is communicated through type. Typography conveys or obscures and gives voice to our message in one fashion or another" (Kahn \&Lenk, 1998 , p. 16). Because fonts give form to the written words, they speak to people. People always appreciate the fonts they like and complain the ones that they don't like but they have to use (Friedman, 2009).

Many researchers consider serif fonts more legible and it is because of their serifs which add more information to the eyes (Geske, 1996) and enhance the legibility of a text by helping the readers to distinguish the letters and words more easily (McCarty \& Mothersburgh, 2002). Geske (1996) has quoted designer Chuck Bigelow who has recommended serif fonts for print because their serifs do not pick up much space in print but they take up much bigger proportion of the information on-screen comparing with that in print.Also Mills and Weldon's (1987) research on paper shows that the texts which have descenders are easier to read comparing to the texts that do not have descenders.

But Tetay and Pera (2011) are against the prominence of serif fonts. They have presented two reasons for the prominence of sans serif fonts over serif fonts: First, serifs are not parts of letters and they have been added to the letters. Consequently as Woods, et al. (2005) have mentioned, serifs in serif fonts act as visual noise when the readers' eyes attempt to detect the letters and words. Second, the space between letters in serif fonts is slightly reduced due to the ornaments that they have. The reduction of the space leads to other problems: One is a problem which is called lateral masking or crowding which is hindering of letter recognition when a letter is flanked by other letters (Geiger \& Lettvin, 1987; cited in O'Brien, Mansfield, \& Legge, 2005) and the other is that letter position coding may be hindered which decreases the ability of word recognition (Perea, Moret-Tatay, \& Gomez, 2011).

Findings of De Lange, Esterhuizen, and Betty (1993) were different from the others. They wanted to determine the legibility of serifs compared to sans serifs. For doing so, they used four tests: A word recognition test, speed of reading test, comprehension test, and a scanning test. They used accuracy, speed and comprehension as the criteria for measuring legibility. The results of their tests supported their hypothesis of equal legibility between serif typefaces and sans serif typefaces. In their study, the subjects could not read the texts with serif fonts faster, they could not comprehend them better and also they were not able to find a word in those texts easier.

\subsection{Size Selection}

Size of type has been always the interest of researchers and publishers in relation to the legibility of print (Tinker, 1963). Most of the publishers state that 10 or 11 point size is the smallest one that should be used for books. Although, there is no agreement among them, there is a uniformity of printing (Thinker, 1963).

Geske (1996) conducted a study to find out which point size is suitable for on-screen reading. He used 9, 10, and 12 point sizes in Helvetica but results did not indicate any significant differences. Bernard, Chaparro, Mills, and Halcomb's (2010) finding is similar to that of Geske (1996).Subbaram's (2004) finding is against Geske's (1996) and his supporters.In his study, the largest font which was 14- point size was proven to be more legible.

Delamater (2010) has stated that reading rates could be affected both vertically and horizontally by crowding. As he presents, larger font sizes can make more spaces between lines, therefore, they can decrease crowding. Silver and Braun's (1993) examination on the effect of type size on readability of warnings of the drugs supports Delamater's (2010) idea. They used 8 and 10 point sizes. They concluded from their study that the warning printed in 10 point type was perceived more readable than 8point type.

Legibility of print increases as the size of the characters is increased up to a point which is called "Critical Print Size" or CPS. Decreasing the size of letters below it will decline speed of reading (Rubin et al. 2006). Another issue influencing speed of reading is visual span. Visual span is the number of adjacent letters that can be recognized without moving eyes (Legge, Ahn, Klitz, \&Luebker, 1977). Reading speed declines when visual span gets smaller. For letters which are smaller or even larger than the fluent range, the visual span becomes smaller. Therefore, fewer letters can be recognized in one fixation; consequently reading speed slows down (Legge, \& Bigelow, 2011).

In fact few of the studies related to type design of print were done in real-life situation (Hartley, 2004).The lack of experimentally supported findings highlights the significance of this study. Moreover, this study is a step to understanding the role of typographical factors on reading comprehension and recall. To meet the requirements of the study, the following questions were formulated:

Question 1: Does the use of serif type vs. sans-serif result in differences in reading speed, comprehension, and recalling among Iranian EFL Intermediate learners?

Question 2: Does the choice of type size (10 point, 12 point) result in differences in reading speed, 
comprehension, and recalling among Iranian EFL Intermediate learners?

Question 3: Does the choice of spacing (double spaced or set solid) result in differences in reading speed, comprehension, and recalling among Iranian EFL Intermediate learners?

\section{Methodology}

\subsection{Participants}

The initial sample of this study was 120 Intermediate EFL learners in Urmia Language Center in Urmia. The subjects in the study were male/female learners sampled non-randomly based on their availability to the researchers. To homogenize the subjects in terms of their language proficiency, using a version of Cambridge Placement Test, learners with intermediate proficiency level were chosen for the purpose of the study. The selected subjects were similar in terms of their age range (16-20). For practical limitations, it was not possible to check the students' eyes to find out whether they have normal vision so they were asked to use their glasses if they do not have normal vision. Among the selected subjects 36 of them mentioned that they do not have normal vision and they used their glasses.

\subsection{Materials}

The instruments used in data elicitation procedures were Cambridge Placement Test, Chapman-Cook speed of reading test, reading comprehension tests (from The Man and His World), and a recalling test.

For the Chapman-Cook speed of reading test, the subjects were allowed to do the test after they all mentioned that they learned how to answer the questions. They also were told to be very fast in this section because a time limitation was considered in this part; they were required to put down their pens and not to write anything after the given time ( $2 \frac{1}{2}$ minutes). The mentioned time was divided to two halves and half of it was allocated to first 12 questions and the rest of the time was given to the second 12 questions. This time division was considered because the line spacing of the first 12 questions is different from that of the second 12 questions. The subjects were told that the examiner who also was the instructor would announce the time. After $2 \frac{1}{2}$ minutes, the tests were collected. The score of this part was estimated by the number of correct answers. The score was the number of items the subject completes accurately within the time limit.

For the reading comprehension test, unit four of the book Man and His World was selected ( $\mathrm{r}=.74)$. The test was supposed to be valid since the test items in the passage were consistent with the information items to be tested with intermediate learners. The subjects were told that there was no time limitation and that they could do this part at their own pace, but they were told that it was better to be fast. The score is the number of items the subject completes accurately within the time limit.

Both of the instruments were the same for the subjects except the typographical variables. Font size and type were manipulated between the subjects; different presentation of the text with different font type and font size was randomly assigned to the subjects; however, line spacing was manipulated within the subjects. For some of the students materials were set in set solid and for the others they were set in double spacing.

The recalling test, a 10-item multiple-choice format designed by the researchers, was given to the same subjects who took part in comprehension test two weeks after they completed the reading comprehension test. Although there was no time limitation, they completed the questions in 25 minutes.

\subsection{Procedure}

In the first phase of the procedure, the participants were required to complete two distinct tests. The tests were held in 7 classes, all in the afternoon. Four classes were for males and three for females in two different buildings of Urmia Language Center institute. The subjects were not allowed to lift the papers from their tables during the tests in order to have the same approximate distance from the papers. All testing sessions were in the afternoon and the natural light of the outside was blocked by thick curtains and the only light was the light of fluorescent bulbs. The students were asked to complete two distinct tests in the first exam session. Then after two weeks, they were required to complete recalling test based on the reading text of the first session exam.

\subsection{Data Analysis}

First, attempts were made to apply both numerical and graphical techniques on the collected data to determine the skewness and kurtosis of the data to determine if the data were distributed normally since the proper method of statistical analysis depends upon the distribution of data (Soleimani, 2009). The measures of homogeneity and heterogeneity were also calculated for the purpose of the description of the data characteristics. 


\subsection{Results}

Kolmogorov- Smirnoff test was used to determine whether the scores of reading speed test, reading comprehension test, and recalling test were normally distributed. The results showed that the scores were normally distributed, so parametric independent $t$-test was used.

According to the Table 1, the difference of students' score in reading comprehension test based on font type is not meaningful; therefore, it can be concluded that font type has no influence on reading speed.

Table 1. Comparing students' speed score based on font type

\begin{tabular}{llllllllll}
\hline Font type & & N & M & SD & SEM & Df & T & F & Sig. \\
\hline $\begin{array}{l}\text { Reading } \\
\text { speed test }\end{array}$ & Arial & 42 & 16.14 & 3.68 & 3.68 & 87 & .978 & .166 & .331 \\
\cline { 2 - 9 } & $\begin{array}{l}\text { Bookman } \\
\text { Old Style }\end{array}$ & 47 & 15.40 & 3.43 & 3.43 & & & & \\
\hline
\end{tabular}

$\mathrm{p} \leq .05$

Table 2 shows that the difference of students' score based on font size in reading speed test is meaningful, in other words, score of students in reading speed test with font size 12 is more than their score in the test with font size 10 .

Table 2. Comparing students' reading speed based on font size

\begin{tabular}{llllllllll}
\hline Font size & & N & M & SD & SEM & df & T & F & Sig. \\
\hline $\begin{array}{l}\text { Reading } \\
\text { speed test }\end{array}$ & 10 & 40 & 14.42 & 2.72 & .430 & 87 & -3.335 & 3.444 & .001 \\
\cline { 2 - 10 } & 12 & 49 & 16083 & 3.80 & .543 & & & & \\
\hline
\end{tabular}

$\mathrm{p} \leq .05$

As Table 3 displays, it can be concluded that the difference of students' score in reading speed test based on line spacing is not meaningful and it can be concluded that line spacing differences do not have any effect on reading speed.

Table 3. Comparing students' reading speed based on line spacing

\begin{tabular}{llllllllll}
\hline \multicolumn{2}{l}{ Line spacing } & N & M & SD & SEM & df & t & F & Sig. \\
\hline $\begin{array}{l}\text { Reading } \\
\text { speed } \\
\text { test }\end{array}$ & $\begin{array}{l}\text { Set } \\
\text { solid }\end{array}$ & 41 & 16.51 & 3.80 & .594 & 87 & 1.889 & 2.4 & .062 \\
\cline { 2 - 10 } & Double & 48 & 15.10 & 3.22 & .465 & & & & \\
\hline
\end{tabular}

$\mathrm{p} \leq .0 \overline{5}$

The data of Table 4 reveals that the difference of students' reading comprehension considering font type is not meaningful. The means obtained with the set solid line spacing condition and double line spacing condition were 16.51 and 15.10 respectively. Therefore, font selection does not have any influence on reading comprehension.

Table 4. Comparing students' reading comprehension based on font type

\begin{tabular}{llllllllll}
\hline Font type & & N & M & SD & SEM & df & T & F & Sig. \\
\hline $\begin{array}{l}\text { Reading } \\
\text { comprehension }\end{array}$ & Arial & 37 & 18.37 & 3.80 & 4.89 & 74 & .185 & .229 & .854 \\
\cline { 2 - 9 } & $\begin{array}{l}\text { Bookman } \\
\text { Old Style }\end{array}$ & 39 & 18.17 & 3.22 & 4.17 & & & & \\
\hline
\end{tabular}

$\mathrm{p} \leq .05$ 
Table 5 shows that the mean of students' score in reading comprehension test in font size 10 is 18.65 and the mean of students' score in that exam with font size 12 is 17.82 . Although the mean of students' score in size 10 is more than the mean in size 12 , the difference is not significant and meaningful $(t=.771, \quad p=0.443)$.

Table 5. Comparing students' reading comprehension based on font size

\begin{tabular}{|c|c|c|c|c|c|c|c|c|c|}
\hline Font size & & $\mathbf{N}$ & M & SD & SEM & df & $\mathbf{t}$ & $\mathbf{F}$ & Sig. \\
\hline \multirow[t]{2}{*}{$\begin{array}{l}\text { Reading } \\
\text { comprehension }\end{array}$} & $\begin{array}{l}\text { Size } \\
10\end{array}$ & 41 & 18.65 & 5 & .782 & 74 & .771 & 1.904 & .443 \\
\hline & $\begin{array}{l}\text { Size } \\
12 \\
\end{array}$ & 35 & 17.82 & 4.25 & .72 & & & & \\
\hline
\end{tabular}

$\mathrm{p} \leq .05$

As it can be seen in Table 6, the mean of students' score in reading comprehension test in set solid is 17.46 and the mean of students' score in that test in double is 19.13. Although the mean of scores in double is more than that in set solid, the difference is not meaningful and significant $(p=0.119)$. As a result, it might be concluded that different leadings do not have any effect on reading comprehension.

Table 6. Comparing students' reading comprehension based on line spacing

\begin{tabular}{llllllllll}
\hline Line spacing & & N & M & SD & SEM & df & T & F & Sig. \\
\hline $\begin{array}{l}\text { Reading } \\
\begin{array}{l}\text { Comprehension } \\
\text { Test }\end{array}\end{array}$ & $\begin{array}{l}\text { Set } \\
\text { solid }\end{array}$ & 39 & 17.46 & 4.51 & .772 & 74 & -.5781 & .048 & .119 \\
\cline { 2 - 10 } & double & 37 & 19.13 & 4.73 & .778 & & & & \\
\hline
\end{tabular}

$\mathrm{p} \leq .05$

According to the data of Table $7(p=0.869, \mathrm{t}=.57)$, it can be concluded that the difference of students' score in recalling test with these two font types is not meaningful.

Table 7. Comparing students' recalling based on font type

\begin{tabular}{llllllllll}
\hline Font type & & N & M & SD & SEM & df & t & F & Sig. \\
\hline Recalling & Arial & 37 & 4.54 & 1.78 & .294 & 74 & .39 & .169 & .698 \\
\cline { 2 - 10 } Test & $\begin{array}{l}\text { Bookman } \\
\text { Old Style }\end{array}$ & 39 & 4.38 & 1.69 & .271 & & & & \\
\hline
\end{tabular}

$\mathrm{p} \leq .05$

Based on Table 8, it can be concluded that the difference between students' score in recalling test based on font size is not meaningful.

Table 8. Comparing students' recalling based on font size

\begin{tabular}{llllllllll}
\hline Font size & & N & M & SD & SEM & df & t & F & Sig. \\
\hline Recalling & Size & 41 & 4.31 & 1.88 & .295 & 74 & -.78 & 1.596 & .436 \\
Test & $\mathbf{1 0}$ & & & & & & & & \\
\cline { 2 - 9 } & $\begin{array}{l}\text { Size } \\
\mathbf{1 2}\end{array}$ & 35 & 4.62 & 1.53 & .259 & & & & \\
& & & & & & & & \\
\hline
\end{tabular}

$\mathrm{p} \leq .05$

Table 9 reveals that $p$ value is .603 , so the difference between students' score based on line spacing is not meaningful. 
Table 9. Comparing students' recalling based on line spacing

\begin{tabular}{llllllllll}
\hline \multicolumn{2}{l}{ Line spacing } & $\mathbf{N}$ & $\mathbf{M}$ & SD & SEM & df & T & F & Sig. \\
\hline $\begin{array}{l}\text { Recalling } \\
\text { test }\end{array}$ & $\begin{array}{l}\text { Set } \\
\text { solid }\end{array}$ & 39 & 4.35 & 1.87 & .299 & 74 & -.522 & 2.764 & .603 \\
\cline { 2 - 5 } & double & 37 & 4.56 & 1.59 & .261 & & & & \\
\hline
\end{tabular}

$\mathrm{p} \leq .05$

\section{Discussion of Reading Speed and Comprehension}

\subsection{Type Size}

It was found that type size has a role in determining speed of reading. Type size 12 was read faster than type size 10 ( $\mathrm{p}$ 0.05). This finding was coincident with finding of Lee (2003) who claims that the increase in letter size leads to increase in legibility. McCarthy and Mothersbaugh (2000) and Mills and Weldon (1987) confirm the idea of Lee (2003). Beidler (2006) also has stated that the first thing for improving the legibility is increasing the type size.

The findings of this study, which revealed that size 12 was read faster than size 10, are not surprising. Because as Delamater (2010) presents, larger font sizes can make more spaces between the lines, therefore, they can decrease crowding, and as Silver and Braun (1993) have concluded, the higher legibility of the larger size could be because of creating more visual angel which makes the words and letters more distinguishable.

Another reason that makes the results of this study seem logical is the belief of Tinker and Paterson (1940) which has been summarized in Tinker (1963). They claim that in smaller sizes, eyes have more fixations and move slower and have more pauses for recognizing the letters and words. They have stated that the eye fixation for smaller sizes have fewer words. Also they believe that the perception time for smaller sizes is longer and more regressions take place in reading with smaller sizes.

This study did not find a main effect of different type sizes (size 10 and size 12) on reading comprehension. The result of this study supported the findings of Chandler (2001) and Fuchs, Langenhan, and Hippius's (2008) study investigating the influence of font size on comprehensibility of package inserts. This study also was against the idea of Bloodsworth (1993) that by summarizing other research concludes that font size has an effect on comprehension. The results also did not support Hughes and Wilkins' (2000) idea. Because they believe that when there are fewer words in a page, the readers have to process fewer words in each page, and consequently their comprehension becomes better. Based on what they suggest, with larger fonts there should be less words in a page, so comprehension should be better. This study did not support it, however.

The study is also in contradiction with the finding of Woods, et al. (2005) which confirmed that present legibility of a text affects its readability and the ease of comprehension. Although it was proved that size 12 is more legible, it did not lead to better comprehension.

\subsection{Font Selection}

No main effect was found with different font types. The result obtained is in accordance with the result of the study done by Beymer, Russell, and Orton (2008) and the results of studies by Lange, Esterhuizen, and Betty (1993) who found out equal legibility between serif typefaces and sans serif typefaces. Shaikh's (2005) research also confirms these findings and he has concluded that there is no difference between perceived legibility of serif fonts and sans serif fonts. However, the present study finding is against a lot of findings in the literature. A large group of teachers believe that serif fonts are read faster. For example, Romney (2006) has written that serif fonts are believed to be read faster due to their invisible horizontal line made by serifs, so it increases the saliency of letters as Arditi and Cho (2004) have stated. Another reason for their belief about superiority of serif fonts over sans serif fonts is that the horizontal strokes that sit along the baseline help the readers to track the lines easier; therefore, they lead to faster and more efficient reading (Rubinstein, 1998, as cited in Arditi \& Cho, 2004).

Maybe the result of this study could be justified by the idea of Zuzanolicko (cited in Grace, 2003). Zuzanolicko maintains that the typefaces are not legible by nature but it is the familiarity of the readers which gives that feature to typefaces. The subjects of this study were exposed to both typefaces in their books and reading materials. Therefore, maybe it can be concluded that their familiarity to both typefaces was same and consequently serif type was as legible as sans serif for the subjects. Font selection did not provide any main effect on comprehension. This finding confirms the result of study done by Chandler (2001).It is not in accordance with the idea of Pardo (2004) that maintains features of a text affect reading comprehension. 


\subsection{Line Spacing}

Line spacing did not reveal a main effect with regard to legibility in this study. As it was discussed widely in the review of literature, nearly all researchers believed that line spacing has an impact on reading speed (Scales, n.d.; Hooper \& Hannafin, 1986). Set solid is tiring of eyes because single line spacing requires more fixations in each line which means fewer words could be read in each fixation, so reading time becomes longer (Mills \& Weldon, 1987).

The results of this study did not support the findings of other researchers. Nearly all researchers believe that leading plays a very important role in reading speed and legibility and they rejected set solid because of its low legibility, but the result of this study revealed that there is no difference in legibility of the text with set solid or double.

Line spacing was not found to provide any effect on comprehension. It did not support what Samuels (1983) believes. He presents that reading comprehension is under the influence of physical characteristics of a text and line spacing is one of those characteristics. The result even did not support Tracy and Morrow's (2002; cited in Pardo, 2004) idea. They have stated that surface features are important for readers to be able to make meaning.

\subsection{Recall Results}

None of the typographical factors used in this study (font type, font size, and line spacing) provide any effect on recalling. The results of this study were in contradiction with findings of Gasser et al. (2005). They found the prominence of serif fonts over sans serif in recalling. The explanation for this finding as mentioned by them could be due to the familiarity of the subjects with serif fonts. However, in this study there was no superiority in familiarity. Therefore, it could be the probable reason for not finding any effect of font selection on recalling.

\section{Conclusion}

This study contradicts many findings of previous studies. Although there are massive bodies of analysis considering type in print by Tinker (1963) and other researchers (Chandler, 2001), there is no agreement among researchers regarding type in print. Perhaps the problem can be solved with further research and replicating prior research.

This study demonstrates that speed of reading, which is the indicator of legibility, is more sensitive to typographical factors than comprehension and recall. The study shows that it was speed of reading that has important effect on legibility. None of independent variables has any effect on dependent variables. Although this study is not in accordance with many prior studies, it supports Chandler's (2001) finding.

Practitioners should consider that this and some other studies have found size 12 to be read faster than other sizes. Font sizes smaller than $12 \mathrm{pt}$ are not appropriate because of the reasons mentioned above. Font sizes larger than $12 \mathrm{pt}$ are not appropriate, either. One reason for this claim is because of economy. Tinker (1963) maintained the other reason for larger fonts' not being appropriate. As he mentioned, using larger sizes make the peripheral vision perceive fewer words and consequently speed of reading decreases.

Since this study did not reveal any main difference between the different typefaces over reading speed, comprehension, and recalling, no special type font is suggested for practitioners to use and they are free to choose it themselves. The only point that is important to pay attention to by subjects is the familiarity of the subjects with special typefaces and their preferences.

While there is no provision that shows any main effect of line spacing on legibility, comprehension, and recalling, practitioners are free to make their own decisions. But it is better to take subjects' preference into consideration. Obviously this study supports some prior studies. It leads to some questions, though. A better understanding of these questions will come through further and continued research.

\section{References}

Aberson, D. H. A., \& Bouwhuis, D. G. (1997). Silent reading as determined by eye and visualacuity. Journal of Research in Reading, 20(3), 184-204. Retrieved May 25, 2011, from http://alexandria.tue.nl/repository/freearticles/617401.pdf

Arditi, A., \& Cho, J. (2005). Serifs and font legibility. Vision Research, 45, 2926-2933. http://dx.doi.org/10.1016/j.visres.2005.06.013

Beidler, P. (2006). Optimized typesetting by Read how you want. Retrieved 20 May, 2011, from http://www.peytonstafford.com/images/ReadHowYouWant_White_Paper.pdf

Bernard, M. L., Chaparro, B. S., Mills, M. M., \& Halcomb, C. C. (2002). Examining children's reading performance and preference for different computer- display text. Behavour\&Information Technology, 21(2), 
87-96. http://dx.doi.org/10.1080/01449290210146737

Beymer, D., Russell, D., \& Orton, P. (2008). An eye tracking study of how font size and type influence online reading. People and computers XXII : culture, creativity, interaction : proceedings of HCI 2008, the 22nd British HCI Group annual conference (Vol. 2). Presented at the 22nd British HCI Group annual conference, Liverpool John Moores University, UK: British Computer Society. Retrieved May 25, 2011, from http://www.bcs.org/upload/pdf/ewic_hc08_v2_paper4.pdf

Bloodsworth, J. G. (1993). In Legibility of print. Retrieved February 22, 2011, from http://www.eric.ed.gov/PDFS/ED355497.pdf

Chandler, S. B. (2001). Running Head: Legibility and comprehension of onscreen type (Doctoral dissertation). Retrieved from http://scholar.lib.vt.edu/theses/available/etd-11172001-152449/unrestricted/chandler.pdf

Delamater, W. E. (2010). How larger font size impacts reading and the implications for educational use of digital text readers. Retrieved July $12, \quad 2011, \quad$ from http://www.ereadia.com/research/How_Larger_Font_Size_Affects_Reading.pdf

De Lange, R. W., Esterhuizen, H. L., \& Beatty, d. (1993). Performance differences between Times and Helvetica in a reading task. Electronic Publishing, 6(3), 241-248. Retrieved May 26, 2011, from http://cajun.cs.nott.ac.uk/compsci/epo/papers/volume6/issue3/rudi.pdf

Friedman, J. J. (2009). A note on the type. Font designers imagine a better-looking web. Technology Review. Retrieved March 2, 2011, from http://www.technologyreview.com/article/23503/

Fuchs, J., Heyer, T., Langehan, D., \& Hippius, M. (2008). Influence of font sizes on the readability and comprehensibility of package inserts. Pharm. Ind, 70(5), 584-592. Retrieved March 2, 2011, from http://www.paint-consult.de/de/publikation/pdf/PAINT-

Gasser, B., Boeke, J., Haffernan, M., \& Tan, R. (2005). The influence of font type on information recall. North American Journal of Psychology, 7(2), 181-188. Retrieved May 25, 2011, from http://www.stcsig.org/mgt/docs/The\%20Influence\%20of\%20Font\%20Type\%20on\%20Information\%20Rec all.pdf

Geske, J. (1996). Legibility of sans serif type for use as body copy in computer mediated communication. Retrieved from Eric data base (ED399 590).

Hartley, J. (2004). Designing instructional and informational text. Retrieved March 20, 2011, from http://www.aect.org/edtech/34.pdf

Hooper, S., \& Hannafin, M. Y. (1986). Variables affecting the legibility of computer generated text. Journal of Instructional Development, 9(4), 22-28. http://dx.doi.org/10.1007/BF02908315

Hughes, L. E., \& Wilkins, A. J. (2000). Typography in children's reading schemes may be suboptimal: Evidence from measures of reading rate. Journal of Research in Reading, 23(3), 314-324. http://dx.doi.org/10.1111/1467-9817.00126

Kahn, P., \& Lenk, K. (1998). Principles of typography for users interface design. MagazineInteractions, 5(6), 15-29. http://dx.doi.org/10.1145/287821.287825

Lee, Y. S. (2003). A study of reading with a handled computer (Master's thesis proposal). Retrieved from http://scholar.lib.vt.edu/theses/available/etd-08192003-112623/unrestricted/Lee_ThesisFinal.pdf

Legge, G. E., Ahn, S. J., Klitz, T. S., \& Luebker, A. (1997). Psychophysics of reading-XVI.The Visual spans in normal and low vision. Vision Research, 37(14), 1999-2010. Retrieved May 26, 2011, from http://vision.psych.umn.edu/groups/gellab/read16.pdf

Legge, G. E., \& Biglow, C. A. (2011). Does print size matter for reading? A review of findings from vision science and typography. Journal of Vision, 11(5), pii.8. http://dx.doi.org/10.1167/11.5.8

Lynch, P. J., \& Horton, S. (1999). Typography. Retrieved March 20, 2011, from http://web.utk.edu/ wratchuk/itce578/weekend/Typography.pdf

McCarthy, M. S., \& Mothersbaugh, D. L. (2002). Effects of typographic factors in advertising-based persuasion: A general model and initial empirical tests. Psychology \&Marketing, 19(7-8), 663-691. http://dx.doi.org/10.1002/mar.10030

Mills, C. B., \& Weldon, L. J. (1987). Reading text from computer screens. ACM ComputingSurveys, 19(4), 329-358. http://dx.doi.org/10.1145/45075.46162

Mizener, S. (n.d.). Typography. Technology Education at WMAHS. Retrieved January 20, 2012, from 
http://www.studygs.net/citation.htm

Nanavati, A. A., \& Bias, R. g. (2005). Optimal line length in reading- A literature review. Visible Language, 39(2), 121-145. Province: Rhode Island School of Design.

Oberauer, K., \& Kliegl, R. (2001). Beyond resources: Formal models of complexity effects and age differences in working memory. European Journal of Cognitive Psychology, 13(1/2), 187-215. http://dx.doi.org/10.1080/09541440042000278

O'Brien, B. A., Mansfield, J. S., \& Legge, G. E. (2005). The effect of print size on reading speed in dyslexia. $J$ Res Read, 28(3), 332-349. http://dx.doi.org/10.1111/i.1467-9817.2005.00273.x

Pardo, L. S. (2004). What every teacher needs to know about comprehension. The ReadingTeacher, 58(3), 272-280. Retrieved May 30, 2011, from http://www.jstore.org/stable/20205476

Perea, M., Moret-Tatay, C., \& Gómez, P. (2011). The effects of inter letter spacing in visual word recognition. ActaPschologica, 137, 345-351. http://dx.doi.org/10.1016/j.actpsy.2011.04.003

Rand Reading Study Group. (2002). Reading for understanding: Towards an R\&D program in reading $\begin{array}{llll}\text { comprehension. } & \text { February 20, 2012, from }\end{array}$ http://www.rand.org/content/dam/rand/pubs/monograph_reports/2005/MR1465.pdf

Romney, C. (2006). Improving the visual appeal of classroom handouts. JALT2005 Conference Proceeding. Tokyo: JALT. Retrieved May 26, 2012, from http://jalt-publications.org/archive/proceedings/2005/E121.pdf

Samuels, J. S. (1983). A cognitive approach to factors influencing reading comprehension. The Journal of Educational Research, 76(5), 261-266. Retrieved March 22, 2011, from http://www.jstor.org/stable/27539984

Scales, A. Y. (n.d.). Improving instructional materials by improving document formatting. Unpublished paper presented at ASEE southeast section conference, North Carolina. Retrieved May 25, 2011, from http://155.225.14.146/asee-se/proceedings/ASEE2002/P2002060INSTRSCA.PDF

Shaikh, A. D. (2005). Psychology of onscreen type: Investigations regarding typefacepersonality, appropriateness, and impact on document perception. (Doctoral dissertation). Retrieved from $\mathrm{http} / / /$ www.google.com/\#hl=en\&sugexp=frgbld\&gs_nf=1\&cp=28\&gs_id=6y\&xhr=t\&q=psychology + of + on screen+type:\&pf=p\&sclient=psyb\&oq=psychology+of+onscreen+type:\&aq=f\&aqi $=\& a q l=\& g s \_l=\& p b x=1$ $\&$ bav $=$ on.2,or.r_gc.r_pw.r_qf.,cf.osb\&fp $=$ d1 cb6253d6261c3c\&biw $=1280 \& b i h=653$

Sheedy, J. E., Subbaram, M. V., Zimmerman, A. B., \& Hayes, J. R. (2005).Text legibility and letter superiority effect. Human Factors: The Journal of the Human Factors and Ergonomics Society, 47(4), 797-815. http://dx.doi.org/10.1518/001872005775570998

Silver, N. C., \& Braun, C. C. (1993). Perceived readability of warning labels with varied font sizes and styles. Safety Science, 16(5-6), 615-625. http://dx.doi.org/10.1016/0925-7535(93)90026-A

Soleimani, H. (2009). Non-Parametric statistics for applied linguistics research. Tehran: Rahnama Press.

Subbaram, V. M. (2004). Effect of display and text parameters on reading performance (Doctoral dissertation). Retrieved from http://etd.ohiolink.edu/view.cgi/Subbaram\%20Venkiteshwar\%20Manoj.pdf?osu1089408221

Subburamu, S. (2010). Does ugliness affect judgment? The effect of typography on movie choice. Retrieved May 26, 2011, from http://psych.nyu.edu/pelli/pubs/subburamu2010intel.pdf

Tetay, C. M., \& Perea, M. (2011). Do serifs provide an advantage in the recognition of written words? Journal of Cognitive Psychology, 23(5), 619-624. http://dx.doi.org/10.1080/20445911.2011.546781

Thangaraji, J. (2004). Fascinating fonts; is the power of typography a marketing myth. Retrieved January 20, 2012, from http://praxis.massey.ac.nz

Tinker, M. A. (1963). Legibility of print. Ames, IA: IOWA State University Press.

Vanderschantz, N. (2008). Reviewing the understanding of the effects of spacing on children's eye movements for on-screen reading. Retrieved March 25, 2011, from http://www.cs.waikato.ac.nz/pubs/wp/2008/uow-cs-wp-2008-06.pdf

Van Rossum, \& M. C. W. (1998). Measuring font legibility. Retrieved May 26, 2011, from http://homepages.inf.ed.ac.uk/mvanross/reprints/legibility.pdf

Woods, R. J., Davis, K., \& Scharff, L. V. F. (2005). Effects of typeface and font size on legibility for children. American Journal of Psychological Research, 1(1), 86-102. 